\section{Labs worth visit}

SIR - Your cheap sneer (Nature 15 March, p.24) that "many once adventurous laboratories have become places where ageing investigators brood on their pension rights" perhaps reflects the fact that your reporters are no longer visiting these laboratories. If they did, they would recognize the exciting and high calibre research which is being conducted against a background of continuing cuts in both staff and equipment. They might also recognize the high regard with which these laboratories are held by overseas scientists if we are to judge by the number of requests received from scientists in developed and developing nations alike to visit and work in these laboratories.

J. N. R. JEFFERS

The Institute of Terrestrial Ecology,

Merlewood Research Staton,

Grange-over-Sands,

Cumbria LA11 6JU, UK

\section{Nuclear abstracts}

SIR - M. A. Bray (Nature 307, 206; 1984) had expressed concern about the large number of abstracts appearing in databases. J. R. Metcalfe (Nature 308, 222; 1984) questioned whether conference abstracts should even be included in databases.

For the nuclear physics bibliographic databases maintained at the US National Nuclear Data Center (NNDC), secondary references such as meeting or conference abstracts and dissertation abstracts are routinely coded. In the bibliography to neutron-induced reactions (CINDA system), all references to a given research work (either experimental or theoretical) are blocked together in the database. Abstracts are entered with a "no book flag"'so that they never appear in the semiannual cumulative publication, unless the abstract constitutes the only reference in that block. However, all entries can be obtained in a computer retrieval. The same was true for the charged particle induced reaction bibliography (CPBIB) system.

For the nuclear structure bibliography (Nuclear Structure References system) which is published thrice annually, there is no blocking. However, the secondary references appear in a section separate from the primary journal listings. In support of Metcalfe's arguments in favour of inclusion, the interval between an initial abstract and a published paper can be from one to five years. This time factor is significant (1) to alert a potential researcher that another group is already working on the same problem which could possibly avoid duplication and wasted research funds and (2) to direct a potential user to the researcher for more details on the work prior to publication.

National Nuclear Data Center,

NORMAN E. HOLDEN

Brookhaven National Laboratory,

New York 11973, USA

\section{They are not alone}

SIR - Is the individual research scientist becoming an endangered species, as more and more disappear into the relative obscurity of "research teams"? An investigation of the pages of Nature suggests that this is indeed the case.

Since 1979, the number of "Letters to Nature" published has been in the region of 1,200 per year. However, throughout this period, there has been a gradual annual reduction in the number of single - and double - author papers coupled with an overall decrease in manuscripts with three named authors. This marked decline has been accompanied by a major increase in the number of multi-author papers.

A breakdown of the 1979 and 1982 quota of Letters to Nature clearly illustrates the change of distribution. During the four years, the decrease in letters with three authors or less was reflected by the steady rise in the average number of authors per letter, the 1982 figure standing at a mean of
3.17 authors per paper which represents a 14 per cent increase overall.

The observed shift towards multiple authorship in Nature, illustrated by the presence in 1980 of a $21 / 2$ page article with 27 named authors, poses the question: has scientific research become specialized to such an extent that individuals must now pool their expertise in order to successfully carry out a research project?

The most likely cause for the conspicuous movement away from singleauthorship is, perhaps the "publish or perish" syndrome. Drastic funding cutbacks in the private and public sectors, worldwide recession and the threat of unemployment have all intensified the pressure on researchers to protect their positions. Being named on as many publications as possible, no matter how remote the connection with the original research work, is one way of proving one's competence.

ANDREW J. CRUMP

40 Ranelagh Road,

London W5 5RG, UK

\begin{tabular}{lcccccccccr}
\multicolumn{8}{c}{ Numbers of Letters to Nature with 1 to } & $\mathbf{9}$ authors in 1979 and 1982. \\
1979 & 1 & 2 & 3 & 4 & 5 & 6 & 7 & 8 & $9+$ \\
1982 & 198 & 448 & 307 & 161 & 65 & 34 & 13 & 9 & 11 \\
Mean change per year & 134 & 360 & 265 & 170 & 83 & 67 & 28 & 17 & 12 \\
$\quad($ expressed as \%) & -9 & -7 & -2 & +5 & +13 & +35 & +42 & +39 & +7 \\
\hline
\end{tabular}

\section{Homer's vino}

SIR - Will someone in the Mediterranean please confirm or refute Wright and Cattley's chemical hypothesis about Homer's "wine-dark sea" (Nature 303, $568 ; 1983)$. I tried with French wine using Copenhagen water that is alkaline enough to turn red cabbage blue, but all I got was a tasteless red fluid. Perhaps "wine dark" refers to the lack of turbidity in wine. Coastal and inland waters are usually turbid whereas the clarity of deep Mediterranean waters off rocky shores could be compared to the clarity of wine. If so, "wine clear sea" would be a better translation and close to the Dutch/Afrikaans (?) wijnkleurige zee quoted by Macnamara (Nature 307, 590; 1984).

The use of oivora noviov as a fixed Homeric metaphor without necessary reference to colour has an analogue in modern English. What is the skin colour of most of the white men you have seen recently?

Waste Management

$\&$ Research, Editorial Office, 1606 Copenhagen $V$, Denmark

\section{Exciting news}

SIR - Your reviewer (Nature 307, 765; 1984) suggests that some results may "titivate". It is hard to see how they could spruce up either themselves or your readers, although the results might well agreeably excite (titillate) at least the latter.

Department of Mathematics, R. P. BOAs

Northwestern University, Evanston, Illinois 60201, USA

\section{Only correct}

SIR - Two errors are becoming commoner in scientific writings.

(1) The word "only" is being shifted forward, away from the word it modifies. Note the differences among the following: " Only I saw the white shark"' (no-one else was on deck). "I only saw the white shark" (I didn't actually catch it). And "I saw only the white shark" (there were no grey ones around).

(2) Within the past few years the word "within" has been supplanting the simpler "in", usually without cause. Rats live within cages, particles sediment within a limited space, trees within a given area grow and die. In such contexts, what is wrong with using "in"?

\section{Scripps Institution of \\ Oceanography,}

University of California, San Dię̌ 0 , La Jolla,

California 92093, USA

\section{The real thing}

SIR - Your correspondence columns have recently contained proposals for various "opposites" to placebo. The Germanspeaking world has used Verum, "the true thing", happily for years as an antonym to placebo. I managed to use it in an English language journal (J.R. statis. Soc. A 146, $386 ; 1983$ ), although the editors insisted on printing it in italics.

92 Hammersmith Grove, London $W 67 H B, U K$
IAN CLARK 